\title{
Ecological sensitivity evaluation of Libo County Based on GIS
}

\author{
Youzhi AN ${ }^{1,2, a}$, Fengtai ZHANG ${ }^{1,2, b}$ and Xia LUO ${ }^{1}$ \\ ${ }^{1}$ School of Geography and Tourism, Guizhou Education University, Guiyang 550018, China \\ ${ }^{2}$ Guizhou Provincial Key Laboratory of Geographic State Monitoring, Guiyang 550018, China \\ aanyouzhi@163.com, ${ }^{b}$ zhfthero@126.com
}

\begin{abstract}
Keywords: Ecological Sensitivity, Ecological Environment, Libo County, Tourism Industry Abstract: Ecological environment and natural resources are the basis for the development of tourist cities. During tourism development, the ecological environment and natural resources will be greatly challenged. These activities may affect the environment, so the construction of tourism activities should be carried out based on environmental ecological sensitivity. Make tourism activities as far as possible do not affect the original ecological environment. According to the actual situation of Libo County, 5 different factors of vegetation, elevation, slope, soil and geological hazard in Libo county were selected as the ecological sensitivity evaluation indexes of the ecological environment in Libo county. Using ArcGIS software and taking the method of factor weighted superposition analysis, we get the sensitivity distribution map of each single factor and comprehensive analysis in Libo county. The results showed that the ecological sensitivity of Libo county was at a high level. The high sensitivity, medium sensitivity, low sensitivity and insensitivity in the region accounted for $21.72 \%$, $34.50 \%, 29.22 \%$ and $14.55 \%$ of the area respectively.
\end{abstract}

\section{Introduction}

The ecological environment is composed of many different factors. Each ecological factor has a certain limit to human activities and natural activities. However, the ecological sensitivity is the analysis of the carrying capacity of various factors to environmental problems [1-3]. After obtaining the adaptability of different ecological factors, we rationally arrange the production and life of human beings, so as to reduce the degree of destruction of the ecological environment. Ecological sensitivity is the assessment of the environmental carrying capacity of ecological factors. According to the environmental situation in Libo County, we can evaluate the probability of environmental damage by ecological sensitivity. Libo County, located in the southeast of Guizhou Province in the Midwest of China, has a remarkable Karst and rocky desertification terrain, making the environment of Libo county a more sensitive and vulnerable zone [4]. Libo county is rich in tourism resources. With the implementation of national policies to tourism, a large number of related policies have promoted the rapid development of tourism. The extensive or irrational exploitation of tourism resources has caused great damage to the environment, and the application of ecological sensitivity evaluation is the basic and necessary path to solve this series of problems[5].

\section{Research Area}

Libo county is located in the southern part of Guizhou Province, its southeast and Guangxi, Guizhou Province in Dushan County. Libo County, Yuping Town, Chaoyang Town, Maonan Town, Lihua Town, Jiarong Town, Jiliang Town, Xiaoqi Town, a total of 7 towns, the population is mostly concentrated in the town of Yuping and the town of Jiang Liang. Libo county is a subtropical humid climate. Because of the low geographical latitude of Libo County, the terrain and geomorphology types are complex and varied, and the climate types are varied. Therefore, the humid climate of the subtropical plateau mountain monsoon is remarkable. 


\section{Data and Methods}

The remote sensing data used in this study are Google Earth HD images, with a spatial resolution of 0.27 meters and a time of September 30, 2013. The land use data of two periods in Libo county were obtained by artificial digitalization, and the relevant data of the vegetation coverage in Libo county were collected, and the accuracy of the land use information was checked.

\section{Evaluation Factor and the Classification of Rank}

Natural environment and human activities will have an impact on the ecological environment. Therefore, when evaluating the ecological sensitivity of the ecological environment, we should try to select a number of different factors. In order to avoid the overlap of the factors and consider the validity of the data, according to the environmental characteristics of Libo County, 5 factors of slope, elevation, soil, vegetation coverage and geological disaster prone point are selected as the index factors of ecological sensitivity evaluation. According to the impact of various factors on the ecological environment of Libo County, the region is divided into 4 grades of highly sensitive area, moderate sensitive area, low sensitive area and insensitive area. For convenient calculation, 4 grades are assigned to 4, 3, 2 and 1 respectively. The details are shown in Table 1.

\section{Determination of the weight}

Because each factor has different influence on the sensitivity of the ecological environment in the evaluation of ecological sensitivity, each factor has different weights. In order to distinguish the influence size of different factors, this paper uses analytic hierarchy process to determine the weight of each factor. The analytic hierarchy process is a comprehensive evaluation method combining qualitative and quantitative. This method has the characteristics of high logic, systematicness, simplicity and practicality, and is more mature, so the frequency of application is high. After obtaining the weight of each factor, we use consistency check to determine whether the weight is consistent with objective facts. According to the above method, the weight value of Libo eco environmental sensitivity evaluation factor is calculated (Table 1).

\section{Data Processing Method}

Table 1 Classification and weight of ecological sensitivity evaluation factors

\begin{tabular}{|c|c|c|c|c|c|}
\hline \multirow[b]{2}{*}{$\begin{array}{l}\text { Ecological } \\
\text { factor }\end{array}$} & \multirow[b]{2}{*}{ Weight } & \multicolumn{4}{|c|}{ Classification of ecological sensitivity and its score } \\
\hline & & $\begin{array}{c}\text { Highly } \\
\text { sensitive } \\
\text { (4) }\end{array}$ & $\begin{array}{c}\text { Moderate } \\
\text { sensitivity } \\
\text { (3) }\end{array}$ & $\begin{array}{c}\text { Low } \\
\text { sensitivity } \\
\text { (2) }\end{array}$ & $\begin{array}{c}\text { Insensitivity } \\
\text { (1) }\end{array}$ \\
\hline Slope $\left({ }^{\circ}\right)$ & 0.2182 & $>25$ & $15 \sim 25$ & $5 \sim 15$ & $<5$ \\
\hline Elevation $(\mathrm{m})$ & 0.1932 & $>900$ & $700 \sim 900$ & $500 \sim 700$ & $<500$ \\
\hline Vegetation & 0.2824 & $>0.42$ & $0.47 \sim 0.61$ & $0.61 \sim 0.81$ & $<0.81$ \\
\hline Coverage $(\mathrm{m})$ & & & & & \\
\hline Soil & 0.1449 & $<0.72$ & $0.6 \sim 0.72$ & $0.3 \sim 0.6$ & $>0.3$ \\
\hline $\begin{array}{l}\text { Geologic } \\
\text { Hazard }\end{array}$ & 0.1613 & $\begin{array}{c}\text { High } \\
\text { incidence } \\
\text { area }\end{array}$ & $\begin{array}{c}\text { Middle } \\
\text { incidence } \\
\text { area }\end{array}$ & $\begin{array}{c}\text { Low } \\
\text { incidence } \\
\text { area }\end{array}$ & $\begin{array}{l}\text { Non onset } \\
\text { area }\end{array}$ \\
\hline
\end{tabular}

ArcGIS10.3 software is used to analyze elements such as raster and raster, re classification, geostatistics and other tools through software transformation tools. Through the cutting tool, each factor is cut from the image layer, the required factors are proposed, the vector data is converted into 
grid data for calculation by using the conversion tool; the slope and elevation data are extracted through the DEM data; the geological disaster points are obtained by the "Guizhou geological disaster warning system" of the Guizhou sky map, and then the nuclear density analysis and the geostatistical analysis tools are used.

\section{Results}

\section{Vegetation Coverage}

Vegetation plays a very important role in the ecological environment of a region. It has the function of self regulation and conservation of the ecological environment in a region. It is one of the reasons that affect the biodiversity in the region.

\section{Slope}

In the ecological environment, the slope degree affects the disaster events such as soil erosion and so on. When the slope is greater than 25 degrees, the ecological sensitivity of the region is high. The slope of the Libo county is mostly between 5 degrees $\sim 25$ and less than 5 degrees and 25 degrees (see Table 1), and the area of the slope of Libo county is $14.94 \%$ of the total area, which is highly sensitive area; the slope is between 15 degree $\sim 25$ and the total surface.

\section{Elevation}

The terrain and landform types of Libo county are complex and diverse. Based on the premise of elevation factors, the area of $>800 \mathrm{~m}$ is divided into highly sensitive areas, accounting for $18.26 \%$ of the total area of the region. The height of $700 \mathrm{~m} \sim 900 \mathrm{~m}$ and $500 \mathrm{~m} \sim 700 \mathrm{~m}$ is divided into moderate sensitive areas and low sensitivity, and $52.90 \%$ and $24.06 \%$ of the total area are the main types of regional elevation respectively, mainly in the West and small seven of the town.

\section{Soil}

The more sticky soil texture is, the better the stability is, and the lower the sensitivity. On the contrary, the more sand texture is, the worse the stability is, the more sensitive it is. The soil type of Libo county is rich and varied, but mainly with lime soil and yellow soil, the soil is divided into 4 grades according to the viscosity of the soil itself, because the viscosity of the yellow soil is higher than the lime soil, so the sensitivity of the lime soil is higher than that of the yellow soil.

\section{Geological Hazard Susceptibility}

From the analysis of the susceptibility of geological hazards, the area of highly sensitive areas in Libo County accounts for $2.02 \%$ of the total area, mainly in the West and southeast of Yuping street in the middle of the region, and in the northern region of the Liming Guan Shui nationality township; the moderate sensitive area accounts for $7.06 \%$ of the total area.

\section{Comprehensive Analysis}

From Figure 1, it can be seen that the ecological sensitivity of most parts of Libo county is moderately sensitive or low sensitive, which accounts for $34.50 \%$ and $29.22 \%$ of the total area, mainly in the north-west, northeastern and southwestern regions of Libo county. The sensitivity of the central, south-west and southwestern regions is high, probably in the Maonan, liming and small seven hole areas, and the high sensitivity area accounts for $21.72 \%$ of the total area, which is less than the medium sensitive and low sensitive. In the highly sensitive area, geological hazards are prone to occur, vegetation coverage is high, the distribution of calcareous soil is large, the elevation is higher than $900 \mathrm{~m}$, and the gradient is greater than 25 degrees. The insensitive area accounts for $14.55 \%$ of the total area, which is mainly located in the urban construction area of Libo county and the relatively flat area. 


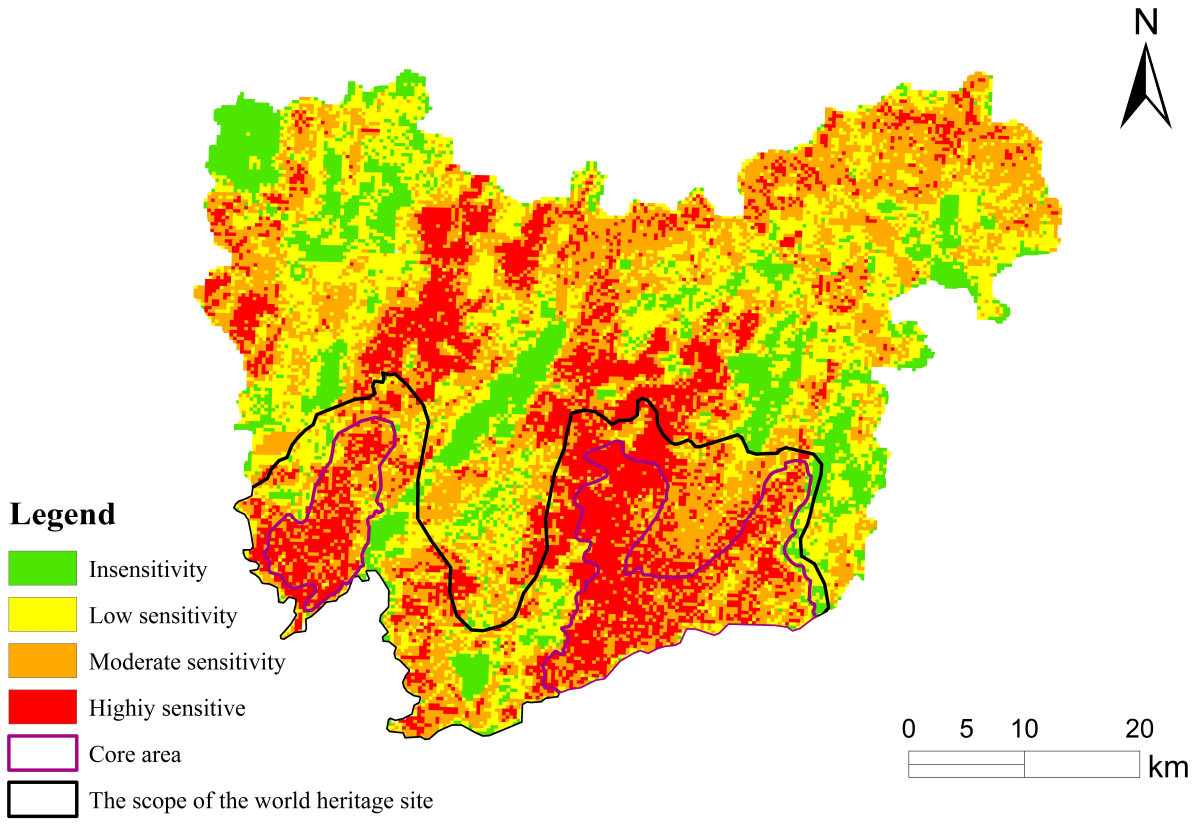

Fig. 1 Comprehensive ecological sensitivity map of Libo County

\section{Sensitivity Analysis of the Scope of World Heritage}

As can be obtained from Figure 1, most of the ecological sensitivity of the heritage site is highly sensitive, mainly in the south of the Liming Guan Shui nationality township, the small part of the southwest of Maonan town and the small town of Xiaoqi town. Because of the high vegetation coverage and large slope, the area has high ecological sensitivity and fragile eco-environment. In the world heritage area, the ecological sensitivity of Yao Shan township is low sensitive and insensitive, and a small part is highly sensitive. The ecological sensitivity of the core area within the scope of the world heritage site is highly sensitive and moderately sensitive. The ecological environment of this area is relatively fragile, and it is not easy to carry out the development and construction of the city. In the development of tourism resources, the development and construction of tourism resources should be carried out on the premise of not damaging the ecological environment of the area. In general, the ecological sensitivity of the whole world heritage site in Libo county is high, so the development of tourism in the world heritage site needs reasonable development to avoid damage to the ecological environment of the world heritage site.

\section{Conclusions}

In this paper, Libo County in the southwest of China is taken as the research object. The ecological sensitivity of the ecological environment of Libo county is evaluated by 5 factors, such as vegetation coverage, elevation, slope, soil and geological hazard, so as to form a system for evaluating the sensitivity of Libo county's biological sensitivity (Table 1). According to this index system, through the use of ArcGIS software, the factors of Libo county were analyzed and evaluated, and the various factors were classified and analyzed by the heavy classification method. The whole ecological environment of Libo county was analyzed comprehensively by weighted superposition method. The ecological sensitivity of Libo county was analyzed by the tabulation chart. Based on the analysis results, the reasonable planning of Libo eco tourism development and reasonable suggestions for urban construction are put forward.

\section{Acknowledgements}

This work was financially supported by the Science and Technology Fund of Guizhou Province, China (grant no. [2017]1135); the Science and Technology Fund of Guizhou Province, China (grant 
no. [2015]2121), and the Science and Technology Fund of Guizhou Province, China (grant no. [2016]ZHCH2845).

\section{References}

[1] Wu Pengda,Lu Xuejun,HOU Wei,and YAN Changqing. Evaluation of land ecological sensitivity based on land quality and ecological index. Science of Surveying and Mapping Vol. 41(2016), p. $81-85$

[2] SHEN Ming, SHEN Lei, ZHONG Shuai, ZHANG Chao, KONG Hanxiao. The spatial optimization of mineral industrial capacity reduction planning of resource-based cities in China based on ecological sensitive areas. Resources Science Vol. 38(2016), p. 1962-1974

[3] Dang Guofeng, Ji Shuzhi. Ecological Sensitivity Evaluation Based on GIS in Qinba Mountainous Area-A Case Study of Longnan Mountainous Area. Chinese Agricultural Science Bulletin Vol. 33(2017), p. 118-127

[4] XIE Yating, ZHOU Zhongfa, YAN Lihui, NIU Yinchao, WANG Li. Study on Spatial Variation and Control Measures of Ecological Red Line in Rocky Desertification Sensitive Area of Guizhou Province. Resources and Environment in the Yangtze Basin Vol. 26(2017), p. 624-630

[5] ZHU Dong guo, XIE Binggeng, CHEN Yonglin. The Strategy of Tourism Land in Mountain Tourism City Based on Evaluation of Ecological Sensitivity-A Case Study of Zhangjiajie city. Economic Geography Vol. 35(2015), p. 184-189 